\title{
A investigation of braking system actuators for electric shuttle bus
}

\author{
Sonki Prasetya ${ }^{1}$, Mohammad Adhitya ${ }^{1}$, Hendri DS Budiono ${ }^{1}$ and Danardono Agus Sumarsono ${ }^{1}$ \\ ${ }^{1}$ Department of Mechanical Engineering, Faculty of Engineering, Universitas Indonesia, Kampus Baru UI Depok 16424, Indonesia
}

\begin{abstract}
An electric bus is an environmentally friendly mass transportation. Commonly an electric bus uses standard air braking system with pneumatic cylinder for the main actuator. Nevertheless, this will consume the space allocation, greater weight as well as higher energy conversion loss. This study focuses on how to implement an electric braking system for electric bus application in order to overcome the problems above. There are steps to achieve the goal. A preliminary observation is conducted for an electric shuttle bus in Universitas Indonesia to obtain the pattern of braking system during period of journey. This data is then utilized to compare the energy consumption for this application. The result shows that electric actuator for braking system is a potential alternative prime mover for a braking system in a vehicle particularly in an electric bus. Substituting the conventional braking system actuator into the proposed one saves $2030 \mathrm{kWs}$ energy, decreases weight into $90 \%$ from its conventional system and cuts $700080 \mathrm{~cm} 3$ space in the bus design. Therefore, the optimum component to be selected is the aim for the next work.
\end{abstract}

\section{Introduction}

A mass transportation is one of indicators of the modern country. Green mass transportations are required to ensure the sustainability of the environment particularly in a city. One of the mass transportations commonly used in cities is the bus. Jakarta as the capital city of Indonesia has this type of mass transportation namely Trans Jakarta (Busway). It is just a regular bus system with designated pathways and stops separated from the main road for private vehicles.

An electric bus is one of the promising passenger's vehicle for the future as the development of electric vehicles currently gaining popularity due to the needs and supports from most of policy makers [1]. However, there are numerous work to be done in order to implement this ideal transportation system commercially.

Researches around the world has been working in this sector. Among researches in the electric bus area, the investigations are in several concentrations such as structure design [2] and the charging system of the electric bus $[3,4]$. Other fields of interest are in power trains area [5] and optimization in energy storage system [6] as well as the regenerative braking systems. The Universitas Indonesia has also performed researches in these area for several years [7]. One of the studies focuses in the braking system for an electric bus. As for the consideration, braking system in a commercial diesel bus consumes $10 \%$ of the total energy consumption as seen in Fig.1 [8]. It means that it is the third part of system that consume high energy when driving.
Commonly the braking system in an electric bus has a similar system with the conventional bus particularly in its mechanical parts. Buses use air brake system with pneumatic cylinders as actuators to rotate the S-cam in order to create motion to press the brake pad. Researches in braking system frequently focus in controlling mechanical friction braking with the combination of magnetic braking so called regenerative braking to minimize the energy consumption. However, the mechanical components particularly for the friction braking system remain the same.

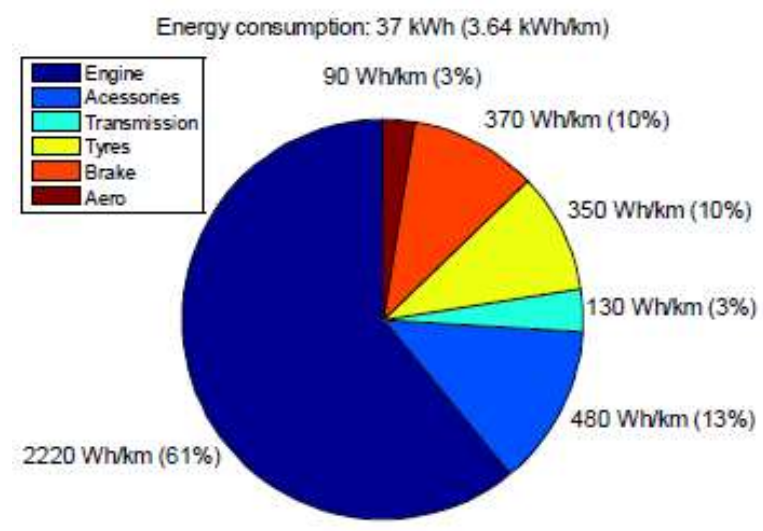

Fig. 1. Energy consumption in a diesel bus [8].

Braking system has main parts namely pneumatic and mechanical. The earlier one consists of compressor, storage reservoir, brake chambers, brake valve, etc. The other one includes slack adjuster, push rods, S-cams,

\footnotetext{
* Corresponding author: hendri@eng.ui.ac.id
} 
brake pads and brake drums. Those last parts are presented in Fig. 2.

Using the mentioned braking system requires a bigger space to put pneumatic subsystem that makes the design of the electric bus has larger volume. Greater volume with the integration of the total components leads to a greater weight. And last, those system contribute higher energy loss due to energy conversions.

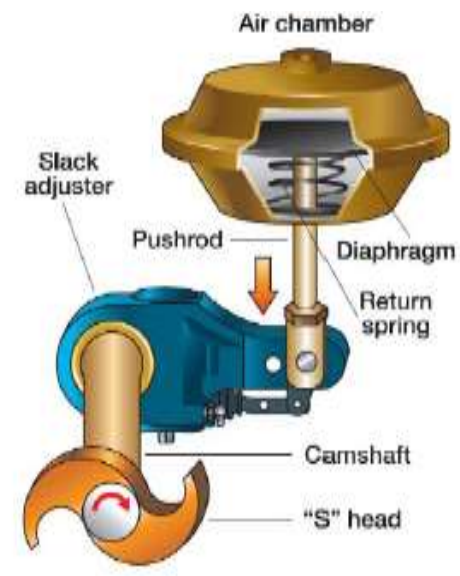

Fig. 2. Mechanical braking subsystem of air brake [9].

The objective of this paper is to provide the base of the research for providing an alternative system for electric vehicle braking system.

\section{Methodology}

There are several stages to implement the idea. First of all the information of electric power consumption of the conventional braking system is monitored to obtain the information of braking application. The electric bus braking system has an electric motor to provide the pressurized air stored in the chamber for activating the pneumatic cylinder when braking pedal is pushed. Fig.2 is the power consumed by the pressurized air braking system. The electrical power $(\mathrm{P})$ is derived from the current (I) multiply it by the voltage (V). Since the signal is an Alternating Current, the voltage of the system is obtained by connecting the voltmeter in $\mathrm{AC}$ mode to the output of inverter via probes. Furthermore, the current is found by using amperemeter via the clamp to a wire of the inverter's output.

$$
P=V \cdot I
$$

where $\mathrm{P}, \mathrm{V}$ and $\mathrm{I}$ are in watt, volt and ampere unit respectively.

The average power consumption is around $2 \mathrm{~kW}$ with the maximum value of nearly $7 \mathrm{~kW}$ at the starting period. Furthermore, we can derived the energy needs drawn from the main energy supply (battery) from this formula.

$$
W=P . t
$$

Where $\mathrm{W}$ and $\mathrm{t}$ (duration) are the energy and time/duration respectively.
The track starts from one bus stop and moves to other 10 stops until it arrives at the similar bus stop due to the route is in a close loop pathway. The average duration to each bus stop is around 1.5 minutes.

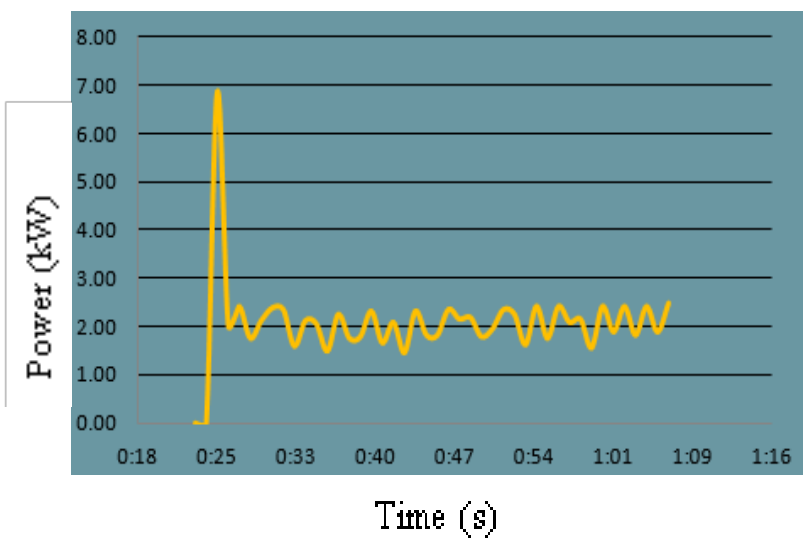

Fig. 2. Power consumption of the compressor for air brake.

Therefore, the energy required for this system in one journey of 17 minutes is $2040 \mathrm{Ws}$.

Second of all, an observation of braking pattern is conducted in order to find braking events in a designated route. Samples of 4 datasets of a bus journey trip are taken. The route has 11 bus stops with circular close loop path in the Universitas Indonesia are observed. One trip is observed around $4.2 \mathrm{~km}$. Fig. 3 shows the route of the shuttle bus.

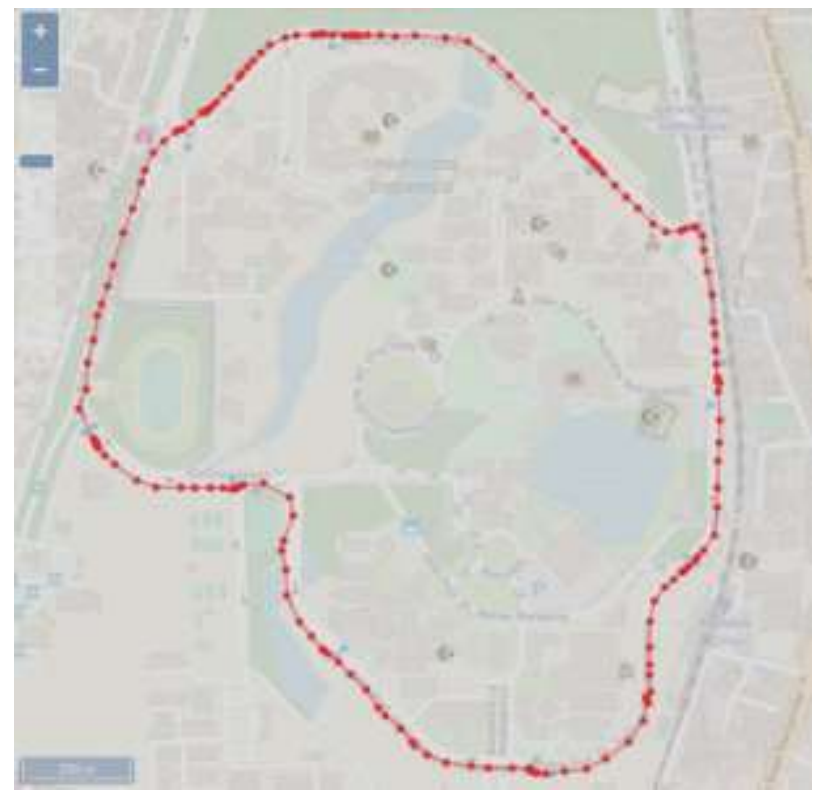

Fig. 3. The bus route.

A case of normal condition is selected. It means that the data is taken during no-rush hour condition with less congestion. Therefore, we can predict the minimum power required for braking application for the conventional system with electric system.

GPS data are collected to obtain the speed every bus stop location as well as the geographical latitude as the indicator of the braking pattern in order to attain the pattern of minimum braking incident that happens during the trip. Fig. 4 shows the average speed during the trip is 
nearly $16 \mathrm{~km} / \mathrm{h}$. The maximum and the minimum speed are around $25 \mathrm{~km} / \mathrm{h}$ and $10 \mathrm{~km} / \mathrm{h}$ respectively. This graph omits the stop period during boarding and un-boarding the passengers. As an addition, the geographical slope is between $+2^{\circ}$ and $-2^{\circ}$ of nearly $80 \mathrm{~m}$ above sea level.

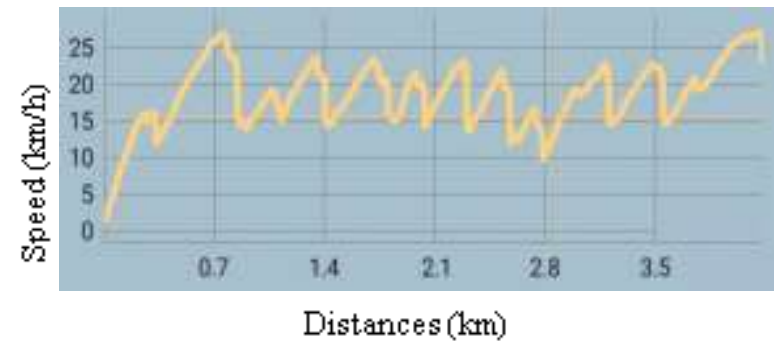

Fig. 4. Speed of shuttle bus.

The braking incident is recorded using a module of electrical instruments attached to a braking pedal of a vehicle and connected to the computer. It consists of a mechanical arrangement to be coupled with the braking pedal. Furthermore, a potentiometer is connected to the active mechanical part to transfer the movement of the pedal into electrical signal before processed by the Arduino controller. The controller reads the analogue electrical signal and translate it into numbers to be interpreted as the intensity of the braking every $200 \mathrm{~ms}$. Fig. 5 shows the experiment arrangement installed in the vehicle for collecting data of braking event.

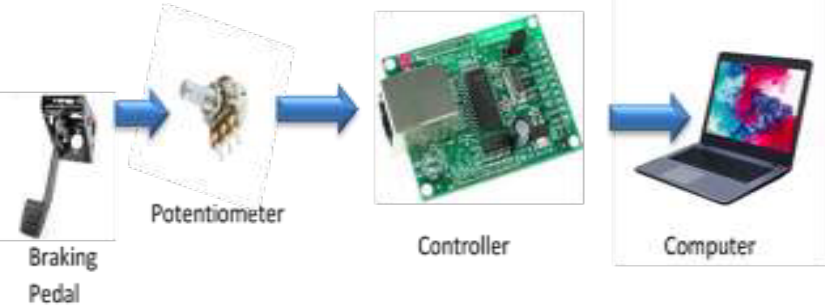

Fig. 5. Speed of shuttle bus.

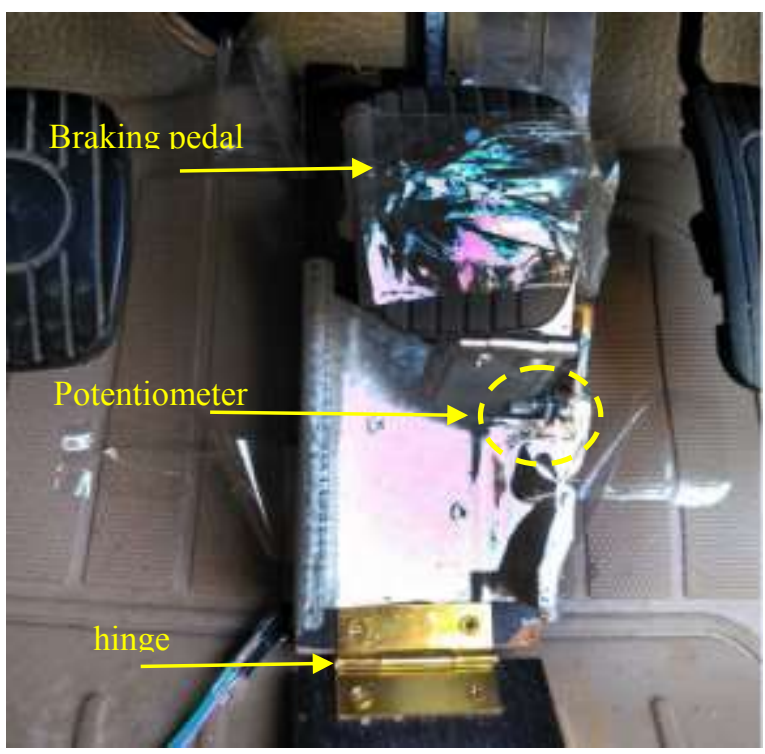

Fig. 6. Braking pedal joined with a mechanical profile to move the potentiometer.
In order to attach the movement sensor namely potentiometer, a mechanical structure with a hinge system is made as Fig. 6.

The graph of braking pattern particularly $1^{\text {st }}$ sample is shown in Fig.7 below. The value represents nothing but the conversion of movement. It is set that the value of no-brake condition (pedal is not hit) is more than 300 . Therefore, values less than that point is considered as braking event.

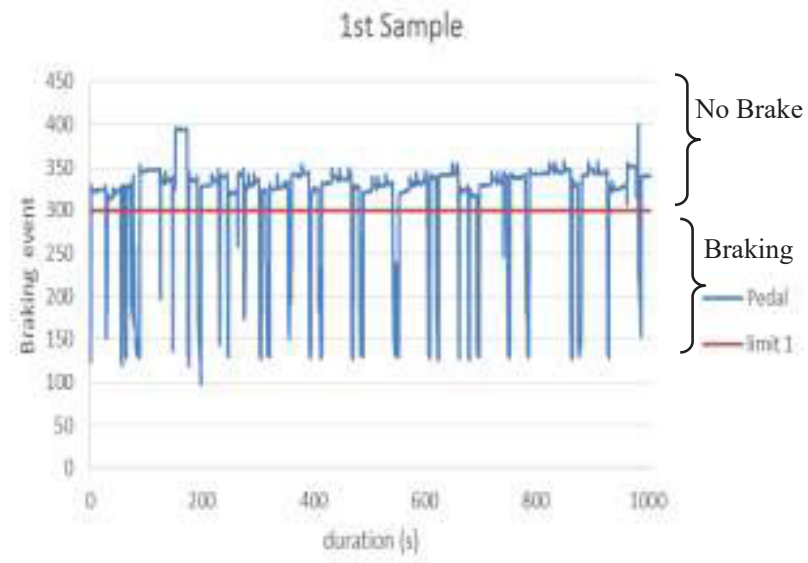

Fig. 7. Braking pattern of a driver in the designated route.

The similar information during the four trips can be presented in the table 1 .

Table 1. Braking event frequency of four dataset

\begin{tabular}{|l|l|l|l|}
\hline \multicolumn{4}{|c|}{ Braking event frequency } \\
\hline $\begin{array}{l}\mathbf{1}^{\text {st }} \\
\text { sample }\end{array}$ & $\begin{array}{l}\mathbf{2}^{\text {nd }} \\
\text { sample }\end{array}$ & $\begin{array}{l}\mathbf{3}^{\text {rd }} \\
\text { sample }\end{array}$ & $\begin{array}{l}4^{\text {th }} \\
\text { sample }\end{array}$ \\
\hline 30 & 29 & 29 & 28 \\
\hline
\end{tabular}

The average of braking incident is 29 times. It means that during a normal condition, a bus driver requires at least 29 times to hit the brake pedal with the given path. However, more braking events possibly occur in unexpected conditions such as rush hours, traffic interruption etc.

\section{Result and Discussion}

We can compare the usage of mechanical actuator by adding the space and the weight required for $2.2 \mathrm{~kW}$ compressor system. Using a data specification from a commercial compressor's distributor [10] we can find that the volume of this system is nearly $320 \mathrm{~m}^{3}$ meanwhile the weight is around $100 \mathrm{~kg}$. The physical measurement for braking system requires $130 \mathrm{~cm} \times 60 \mathrm{~cm} \times 90 \mathrm{~cm}$ space inside the vehicle. Based on the traction forces formula of the vehicle given below [11] we obtain the force requires for braking:

$$
F_{R M}=F_{R R}+F_{\text {aero }}+F_{\text {inter }}+F_{g}+F_{\text {inert }} \text { (3) }
$$


where $F_{R M}, F_{R R}, F_{\text {aero }}, F_{\text {inter }}, F_{g}$, and $F_{\text {inert }}$ are the sum of resistance to movement forces, rolling resistance forces, aerodynamic forces, internal frictional forces, gravitational forces and inertial forces respectively.

Those forces can be multiplied by the distance to get the energy required by the vehicle. The construction design affects the aerodynamic forces and the weight influences the gravitational forces when the route has slopes. It is found from the calculation that the maximum Force needed for the Electric Bus is $1000 \mathrm{~N}$.

As an addition, since the compressor uses AC motor, thus the electrical current need to be transformed from a Direct Current into an Alternating Current with the help of a converter namely inverter. Naturally it has a drawback of efficiency due to the conversion. Normally around $90 \%$ is considered as the efficiency [12]. It means that using electric based actuator will slightly increases efficiency compare to the pneumatic one.

Based on the braking event of around 30 event, it consists of 2 actions namely push and pull actuator conditions. Therefore, the designated route has 60 actions.

Substituting the mechanical (pneumatic) actuator with the electric actuator results in two options namely utilizing magnetic principle for creating braking friction or converting the previous system with the similar moving actuator utilizing electrical motor principle. Indicators for selecting the desired system are minimum modification from its existing type, simple control and also costs. Considering the transportation system uses a specific path, the braking pattern can be predicted, thus the linear actuator is selected as the solution.

A commercial linear actuator with $1000 \mathrm{~N}$ force is required. It consumes only 36 Watt power with the weight only $1.5 \mathrm{~kg}$ and small dimension of $480 \mathrm{~cm}^{3}$. This type actuator is slower than the pneumatic systems response around 1 second for either push or pull action. Therefore, 4 wheels bus for 1 trip requires energy of $8640 \mathrm{Ws}, 6 \mathrm{~kg}$ weight and $1920 \mathrm{~cm}^{3}$ space.

\section{Summary}

Based on the results, we conclude several points that are presented as below.

The electric braking system actuator is a potential alternative to be studied in order to increase the energy efficiency as well as to reduce the weight of the vehicle.

It drops energy consumption into for one trip from $2040 \mathrm{kWs}$ to $8640 \mathrm{Ws}$. Meanwhile, the weight decreases braking system load of the vehicle into more than $90 \%$. Moreover, it requires only $1920 \mathrm{~cm}^{3}$ space in a Bus System.

\section{Recommendation}

The simulation taken in this paper is still based on the calculations. Therefore, an experiment to validate the result is required. A test bed of braking system can be built to observe as well as implement the system in a lab scale prior to the real application. Moreover, the combined braking system using electrical and mechanical actuators is likely preferred for safety precaution at the beginning of the research implementation.

\section{References}

1. Energy, U.D.o., EV Everywhere - grand challenge blueprint, Energy, Editor. 2013, DOE.

2. Kunakro-ong, P., K. Ruangjirakit, and P. Jongpradist, Design and analysis of electric bus structure in compliance with ECE safety regulations, in Intelligent Transportation Engineering 2017. 2017: Singapore.

3. Eltis. Braunschweig Launches World's First Inductive Fast Charging Electric Bus. 2013 [cited 30 December 2017; Available from: http://www.eltis.org/discover/news/braunschweiglaunches-worlds-first-inductive-fast-chargingelectric-bus-germany- 0 .

4. Wu, H.H., et al., A Review on Inductive Charging for Electric Vehicles, in IEEE International Electric Machines \& Drives. 2011.

5. Mahmoud, M., et al., Electric buses: A review of alternative powertrains. Renewable and Sustainable Energy Reviews, 2016. 62: p. 673-684.

6. Zhu, C. and X. Chen. Optimizing Battery Elctric Bus Transit Vehicle Scheduling with Battery Exchanging: Model and Case Study. in 13th COTA International Conference of Transportation Professionals. 2013: Sciences Direct.

7. Widiutomo, A. Mobil Listrik Karya Mahasiswa UI Diklaim Hampir 100 persen Buatan Lokal. 2017 [cited 2018; Available from: http://otodriver.com/article/view/mobil-listrik-karyamahasiswa-ui-diklaim-hampir-100-persen-buatanlokal/2EeHt3rwIPH-k1ppKwfnw IMZ8ptAIdEzqNVekgk6s.

8. Lajunen, A., Evaluation of Electric Buses. 2015, Aalto University.

9. Abd-Ali, N.K., Diaphragm Actuator Design with New Rubber Compounds. Al-Muthanna Journal for Engineering Sciences, 2016.

10. IBIX, Compressors Range IBIX Special Cleaning, IBIX, Editor: Ravenna, Italy.

11. Heryana, G., et al. Power consumption analysis on large-sized electric bus. in International Tropical Renewable Energy Conference 2017. 2017.

12. electric, M., Inverter scroll compressor advantages, M. electric, Editor. 2007. 